\title{
Boundary Layer Flows Along Sloping Surfaces
}

\author{
PREFACE TO THE SPECIAL ISSUE
}

\begin{abstract}
Alan SHAPIRO and Evgeni FEDOROVICH
School of Meteorology, University of Oklahoma, Norman, Oklahoma, USA e-mails: ashapiro@ou.edu; fedorovich@ou.edu
\end{abstract}

This Special Issue of Acta Geophysica on boundary layer flows along sloping surfaces is concerned with the theory and modeling of a range of slopeflow phenomena in the lower atmosphere, including mountain and valley winds, low-level jets, and internal gravity waves. When a sloping surface is heated or cooled, a temperature difference is set up between the air in the surface layer and the environmental air at the same altitude. The buoyancy field associated with this temperature difference projects in the along-slope direction and induces an along-slope flow. In areas where basins are largely sheltered from synoptic effects, slope flows are the building blocks of local weather. Even in cases where synoptic forcing is important, pronounced slope-flow signals may still be apparent. In regions where heavily industrialized population centers extend across variable topography, these local flows exert major controls over energy usage, visibility, fog formation, and air pollutant dispersion. In agricultural regions, these local winds significantly affect microclimates. The slope flows also need to be taken into account in aerial spraying and fire-fighting operations. On the larger scale, persistent slope winds cover vast areas of the earth (e.g., Greenland, Antarctica), and play an important role in the weather and climate of these areas.

Slope flows can be described in their most elemental forms as turbulent natural convection flows along cooled/heated sloping surfaces in a stratified environment. Katabatic flows (resulting from surface cooling) are quite shal- 
low (typical jet maximum occurs in the height range between 1 to $100 \mathrm{~m}$ above ground level), and are therefore poorly resolved in most air pollution models, numerical weather prediction models and global climate models. Although much progress has been made in the conceptual understanding and quantitative description of slope flows, long-standing difficulties with the numerical description of turbulent flows in general and stably-stratified turbulent flows in particular (in the case of katabatic flows), and the myriad variety of flow interactions caused by complex topography and surface inhomogeneity, for example, from irregular snow/ice/soil cover, cloud cover, topographic shading, soil moisture, and land use, make the dynamics of slope flows a rich and challenging area of study. 